\title{
New stem-Phasmatodea from the Middle Jurassic of China
}

\author{
LiANGJIE SHANG ${ }^{1}$, Olivier BÉTHOUX ${ }^{2}$ and Dong REN ${ }^{1 *}$ \\ ${ }^{1}$ College of Life Science, Capital Normal University, 105 Xisanhuanbeilu, Haidian District, Beijing 100048, China; \\ e-mail: rendong@mail.cnu.edu.cn \\ ${ }^{2} 40$ rue d'Aveillans, 38770 La Motte d'Aveillans, France; e-mail: obethoux@yahoo.fr
}

Key words. Adjacivena rasnitsyni gen. n., sp. n., Phasmatodea, Susumaniidae, Heteropteryx dilatata, China, Daohugou, intra-specific variability, sexual dimorphism, fossil, Middle Jurassic

\begin{abstract}
Adjacivena rasnitsyni gen. n., sp. n., from the Middle Jurassic Jiulongshan Formation (Daohugou Village, Inner Mongolia, China), is described based on a set of well-preserved specimens, interpreted as two females and a male of the same species. The new taxon is assigned to the family Susumaniidae, i.e. is a candidate stem-Phasmatodea. This ordinal assignment is supported by genital elements, chiefly a putative operculum concealing the ovipositor observed in one female specimen and a putative extension of the $10^{\text {th }}$ tergum with a thorn pad in the male specimen. Variation in the venation of the forewing is appreciated based on more or less complete pairs of wings and a comparison with that in the forewings of male Heteropteryx dilatata (Parkinson, 1798). This material offers new perspectives on the primary homologies of the hind wing venation of stick-insects.
\end{abstract}

\section{INTRODUCTION}

Stick-insects (also known as Cheleutoptera, Phasmatodea, Phasmida and Phasmatoptera, among others) compose a rather small order of insects, which currently includes over 3,000 extant species (Bragg, 2001; Brock \& Hasenpusch, 2009). The comparatively low extant diversity in this order is mirrored by its rarity in the fossil record: a few tens of species are to varying extents convincingly assigned to this order (Birket-Smith, 1981; Gorochov, 1988, 1992, 1993，1994, 2000; Martynov, 1928; Nel et al., 2004, 2010; Ren, 1997; Sharov, 1968, 1971; Tillyard, 1918; Wedmann et al., 2007; among others). However actual affinities of many fossil taxa remain uncertain (Grimaldi \& Engel, 2005; Tilgner, 2000; and see discussion by Gorochov, 2000; Bradler \& Buckley, 2011, with respect to $\mathrm{Nel}$ et al., 2010; and Delclòs et al., 2008).

This situation is primarily due to the incompleteness of the fossil material, but also to a lack of a clear-cut forewing venation apomorphy for this order. According to Gorochov \& Rasnitsyn (2002), "fore wing with veins subparallel" is the only available character for identifying a stick-insect wing. However, this character is shared by a large number of narrow-winged polyneopteran insects, including, for example, some mantids. In addition the fact that many stick-insects have vestigial forewings reduces the value of this character. Finally, although relevant at the level of the order, the comparative analysis of foreand hind wing venation provided by Ragge (1955), based on extant material, needs to be reinterpreted in a broader context, chiefly because the $\mathrm{CuA}$ vein in the hind wings, which is strongly convex in nearly all polyneopteran insects (possibly nearly all winged insects), is not included in this interpretation (the vein interpreted as
"Cu" is concave). This situation has two interrelated consequences: conjectures about the primary homologies of stick-insect wing venation and the identification of several Mesozoic representatives of the order are both uncertain.

Thus, specimens of Mesozoic fossils on which the details of the hind wings and body are clearly visible are particularly valuable. Herein we describe three new and comparatively complete Jurassic specimens from China that we tentatively assign to Phasmatodea.

\section{MATERIAL AND METHODS}

All the fossil material described is housed in the Key Laboratory of Insect Evolution \& Environmental Changes, Capital Normal University, Beijing, China. The material was collected near Daohugou Village, Jiulongshan Formation, Ningcheng County, Inner Mongolia, China. The age of the Formation is still controversial, but most published biostratigraphic correlations and radiometric dates indicate a Middle Jurassic age (Bathonian - Callovian boundary; Ren et al., 1995, 2002, 2010; Cui et al., 2010; Zhao et al., 2010).

Fossil specimens were examined under a Leica MZ12.5 dissecting microscope and illustrations made with the aid of a drawing tube attached to the microscope. Line drawings were prepared using CorelDraw 12 graphic software. Photographs were taken using a Nikon D100 coupled to a $105 \mathrm{~mm}$ Nikon macro lens and processed using Adobe Photoshop.

Material of Heteropteryx dilatata (Parkinson, 1798) was obtained from an insect dealer. According to the data provided the specimens were collected from wild populations at Tapah, Cameron Highlands (Malaysia) in February 2006. Wings were cut off and mounted on slides in Euparal medium. Photographs were taken using a Canon EOS 400D coupled to a $50 \mathrm{~mm}$ Canon macro lens and processed using Adobe Photoshop.

The systematic arrangement tentatively follows Gorochov (1988, 2000; but see below). Except "Sc" and "RS" are replaced

\footnotetext{
* Corresponding author.
} 
by "ScP" and "RP", respectively, wing venation nomenclature and conjectures of primary homology follow Sharov (1968, 1971; followed by Carpenter, 1992). This does not imply support for this primary homology by the second author. Wing venation abbreviations are as follows: $\mathrm{ScP}$ - posterior Subcosta; $\mathrm{R}$ - Radius; RA - anterior Radius; RP - posterior Radius; MA anterior Media; MA1 - anterior branch of MA; MA2 - posterior branch of MA; MP - posterior Media; CuA - anterior Cubitus; $\mathrm{CuA} 1$ - anterior branch of $\mathrm{CuA} ; \mathrm{CuA} 2$ - posterior branch of $\mathrm{CuA}$; $\mathrm{CuP}$ - posterior Cubitus; $1 \mathrm{~A}$ - first anal vein. Other abbreviations and indications are as follows: LFW - left forewing; RFW - right forewing; LHW - left hind wing; RHW - right hind wing; on Fig. 3, * indicate the claval fold on each forewing. Abbreviations for genital structure follow Bradler (2009). In detail: Gon - gonobasis; Op - operculum; Gap8 gonapophysis 8; Cer - cercus.

\section{SYSTEMATICS}

Order Phasmatodea Brunner von Wattenwyl, 1893

Superfamily Susumanioidea Gorochov, 1988

Family Susumaniidae Gorochov, 1988

\section{Genus Adjacivena gen. n.}

Type species. Adjacivena rasnitsyni sp. n. by present description (monotypic genus).

Composition. Type species and Adjacivenia reticulata (Kuzmina, 1985) comb. n. (but see discussion; originally assigned to the genus Phasmomimoides Sharov, 1968, and then to the genus Eosusumania Gorochov, 1988 by Gorochov, 1988).

Diagnosis. Forewing: MA2 approaching MP + CuA1 a short distance before the middle of the wing (main diagnostic character); MP + CuAl forked (known only for type species). Hind wing (known only for type species): MA1 fused over a moderate distance with RP; MA2 fused with MA1 distal to its divergence from RP + MA1. Legs slender, moderately long and apparently not armed.

Etymology. Generic name derived from the combination of "adjac-" (adjacent in Latin) and "vena" (vein in Latin) referring to the main character of this genus, namely that the vein MA2 approaches MP $+\mathrm{CuA} 1$ in the forewings. Gender: feminine.

Discussion. The occurrence of a RP vein in the forewing that forks near its origin is an uncommon trait in winged insects. This trait is present in the forewing of male Heteropteryx dilatata (extant Phasmatodea; Willmann, 2003: Fig. 12; Fig. 4) and in several genera assigned to the family Susumaniidae (see composition in Gorochov, 2000). Affinities of the new material with Blattinopsidae Bolton, 1925, which also have a RP with basal first fork, can be excluded because: (1) lack of m-cua arculus; (2) lack of comb-like aligned cross-veins; and (3) occurrence of a long ScP.

It is uneasy to apply the systematic treatment provided by Gorochov (2000) to the Susumaniidae. One of the traits considered by this author is the number branches of RP in forewings: this vein is said to be 2-branched in Susumaniinae and 3-branched in Phasmomimoidinae (Gorochov, 2000: 299). However, we observed both states in specimens of the extant stick-insect species, Heteropteryx dilatata (Fig. 4). Another trait considered by
Gorochov (2000) is the location of the first fork of RP in forewings, which he states is located "in proximal wing part" in Susumaniinae and "in middle wing part" in Phasmomimoidinae. However, according to data published by Birket-Smith (1981: Fig. 1D) and Gorochov (2000: Fig. $3 \mathrm{c}$ ) this fork is located about $40.6 \%$ along the length of the wing in Coniphasma rosenkrantzi Birket-Smith, 1981 [a Susumaniinae according to Gorochov (2000)] and $41.5 \%$ along the length of the wing in Phasmomimoides lineatus Sharov, 1968 (type-species of the type-genus of the Phasmomimoidinae). The difference is therefore negligible. Because of this and our limited knowledge of the intra-specific variation in wing venation in Susumaniidae, we propose to compare the material of Adjacivena rasnitsyni gen. n., sp. n. with all taxa assigned to the Susumaniidae by Gorochov (2000).

Palaeopteron complexus Rice, 1969 is documented based on a single specimen, several wings of which overlap. Only a part of the hind wing venation is deciphered by Rice (1969). According to the available data the stem of RP + MA1 ["R2+3" \& "R4+5" according to Rice (1969)] is comparatively long and MA2 ("M1+2") and $\mathrm{MP}+\mathrm{CuA} 1$ ("M3+4") reach $\mathrm{CuA} 2$, which is similar to what occurs in Orephasma eumorpha Ren, 1997, and make Adjacivena rasnitsyni gen. n., sp. n. distinct from these species.

In Adjacivena rasnitsyni gen. n., sp. n. MA2 and MP + $\mathrm{CuA} 1$ are very narrowly separated over some distance. This trait is very probably derived and is absent in Coniphasma rosenkrantzi (Birket-Smith, 1981).

The interpretation of the forewing venation of Promastacoides albertae Kevan \& Wighton, 1981 is not evident from the available data (Kevan \& Wighton, 1981: Fig. 6): the posterior branch of the vein interpreted by Kevan \& Wighton (1981) as "MA" together with "MP" probably form MP + $\mathrm{CuA1}$; the anterior branch of the vein interpreted as "MA" is probably MA2; and the posterior branch of that interpreted as "Rs", the origin of which is unclear, is probably "MA1". It is plausible that there are secondary intercalary veins in the area between the two branches of RP and in that between the posterior branch of RP and MA1. These are absent in our material, in which the cross-veins are reticulated. In addition the coloration pattern differs significantly.

Phasmomimella paskapoensis Kevan \& Wighton, 1981 is only known from a hind wing. In the light of recent discoveries (Ren, 1997; and herein) the posterior branch of "Rs", as indicated by Kevan \& Wighton (1981: Fig. 2), must be interpreted as MA1. In the corresponding material the common stem of RP + MA1 is much longer than in the new material. In addition RA, RP and MA1 follow a sigmoidal course near the apex, a trait absent in Adjacivena rasnitsyni gen. $\mathrm{n}$., sp. $\mathrm{n}$.

Only a single and fragmentary forewing of each species of the genus Eosusumania Gorochov, 1988 is known, except for Eosusumania fusca Gorochov, 1988. In the later, MP + CuA1 is simple (unlike in Adjacivena rasnitsyni gen. n., sp. n.) and this species lacks a narrow area between MA2 and MP $+\mathrm{CuA} 1$. Comparison with 
Eosusumania ornata (Kuzmina, 1985) is impossible due to the extremely fragmentary condition of the material. Although the corresponding material is also fragmentary, both Eosusumania lata (Kuzmina, 1985) and Eosusumania maculata (Kuzmina, 1985) lack a narrow area between MA2 and MP + CUA1. The description of Eosusumania reticulata (Kuzmina, 1985) is based on a basal fragment of a forewing and it cannot be determined whether MP + CuA1 is forked, or simple. Notably, the area between MA2 and MP + CuA1 is narrow in this species.

Prosusumania semenica Gorochov, 1988, and species assigned to the genus Cretophasmomima Kuzmina, 1985 by Gorochov (1988), including Cretophasmomima baissiense (Sharov, 1968) and Cretophasmomima antiqua (Kuzmina, 1985), have a simple MP + CuA1 (Gorochov, 1988; Kuzmina, 1985; Sharov, 1968), while in all specimens of Adjacivena rasnitsyni gen. n., sp. n. this vein forks distally. The condition of this trait in Susumania flexuosa Gorochov, 1988 cannot be determined because the material is incomplete (Gorochov, 1988: Fig. 13), but even if MP $+\mathrm{CuA} 1$ forks in this species, the hypothetical fork would be located in a distal part of the wing, unlike in Adjacivena rasnitsyni gen. n., sp. n. In addition Eosusumania fusca, Prosusumania semenica, Susumania flexuosa and Cretophasmomima spp. lack a narrow area between MA2 and MP + CuA1.

The available material of Cretophasmomimoides reductus Gorochov, 1988 is very incomplete. However, in this species the area between MA2 and MP + CuA1 is of usual width, unlike in Adjacivena rasnitsyni gen. n., sp. n.

Species known only by hind wings compose the genus Paraphasmomimella Kuzmina, 1985, making this taxon of doubtful relevance. Paraphasmomimella longa Kuzmina, 1985 is documented based on a very fragmentary specimen, in which the common stem RP + MA1 ("RS1" \& "RS2" in Kuzmina, 1985) is comparatively long and it is likely that $\mathrm{MP}+\mathrm{CuA} 1$ reaches $\mathrm{CuA} 2$. In all these traits this species differs from Adjacivena rasnitsyni gen. n., sp. n. The species Paraphasmomimella chetanica Gorochov, 1988 is as poorly known as Paraphasmomimella longa. In the former the common stem RP + MA1 is longer than in Adjacivena rasnitsyni gen. n., sp. n. It must be noted that species of the genus Paraphasmomimella closely resemble Hagiphasma paradoxa Ren, 1997 and Aethephasma megista Ren, 1997.

Kolymoptera magadanica Gorochov, 1988, for which the original material was erroneously interpreted as forewings (Gorochov, 2000), has a comparatively long RP + MA1 stem, unlike in the hind wings of Adjacivena rasnitsyni gen. n., sp. n.

Finally Hagiphasma paradoxa, Aethephasma megista and Orephasma eumorpha, all known from exceptionally well-preserved specimens with fore- and hind wings, differ from Adjacivena rasnitsyni gen. n., sp. n. as follows: (1) lack of narrow area between MA2 and MP + $\mathrm{CuA1}$ (posterior branch of "MA" - anterior branch of "MP" according to Ren, 1997) in forewings, and (2) comparatively long RP + MA1 stem ("Rs" and "MA" in Ren,
1997) in hind wings. In addition, as mentioned above, MA2 ("MP") and MP + CuA1 ("CuA") reach CuA2 ("CuP") in Orephasma eumorpha, unlike in Adjacivena rasnitsyni gen. n., sp. n. In Hagiphasma paradoxa and Aethephasma megista $\mathrm{MP}+\mathrm{CuA} 1$ reaches $\mathrm{CuA} 2$, this derived trait is absent in Adjacivena rasnitsyni gen. $\mathrm{n}$.

In summary, a single species might be related to the material we describe: Eosusumania reticulata has a narrow area between MA2 and MP $+\mathrm{CuA} 1$, as in Adjacivena rasnitsyni gen. n., sp. n. and unlike other species. This unique condition might indicate a close relationship between these species. In the absence of further data, we cannot properly test the hypothesis that Adjacivena rasnitsyni gen. n., sp. n. and Eosusumania reticulata are related: many characters of the forewing venation (such as the total number of RP and MP $+\mathrm{CuA} 1$ branches) and hind wing morphology of the latter are unknown. The proposed assignment to the new genus Adjacivena must be considered as tentative.

Assuming a close relationship between Adjacivena rasnitsyni gen. n., sp. n. and Eosusumania reticulata, the latter has forewings uniformly dark except along main veins and cross-veins (Kuzmina, 1985: Pl. V, Fig. 7), unlike in the former (either female or putative male). Therefore, the erection of a distinct species is valid.

\section{Adjacivena rasnitsyni sp. $\mathrm{n}$.}

(Figs 1-3)

Diagnosis. The forewing of the female is darkly coloured, with pale spots forming 4 transverse stripes and in the presumed male alternating pale and dark areas occur.

Descriptions. Specimen CNU-PHA-NN2009001 (holotype; Fig. 1): incomplete individual, head and most part of thorax obscured, abdomen incomplete, fragments of a right hind? femur, and of a femur and tibia of a right leg (Fig. 1B; the latter preserved on negative imprint only), two complete forewings, an incomplete left hind wing and very incomplete right hind wing; body length (as preserved) about $36 \mathrm{~mm}$. Forewings: preserved length 44.4 $\mathrm{mm}$ / about $41 \mathrm{~mm}$ (right / left forewing), width about 12 $\mathrm{mm} / 12.5 \mathrm{~mm}$; area between anterior wing margin and $\mathrm{ScP}$ wide in proximal part, tapers gradually towards wing apex; in proximal part, veinlets from ScP with many irregular cross-veins between them; ScP hidden under R basally; ScP long, reaching anterior margin of wing close to wing apex; RA more or less parallel to $\mathrm{ScP}$, with few cross-veins between RA and ScP; RP branched $27.1 \mathrm{~mm} /$ $26.7 \mathrm{~mm}$ distal to its origin; anterior branch of RP forked, posterior branch forked distally / simple; MA forks basal to the origin of RP, with an anterior branch forked distally and a posterior branch simple; posterior branch of MA weak and concave, closely approaches the middle of $\mathrm{MP}+\mathrm{CuA} 1$ but does not join it. MP + CuA1 branching distal to the narrow MA / MP + CuA1 area; $\mathrm{MP}+\mathrm{CuA} 1$ basally straight and distally curved, reaching wing apex, posterior branch of MP + CuA1 S-shaped; area between $\mathrm{MP}+\mathrm{CuA} 1$ and $\mathrm{CuA} 2$ broader distally; $\mathrm{CuA}_{2}$ separated from $\mathrm{MP}+\mathrm{CuA} 1$ at wing base; $\mathrm{CuA} 2$ more or less straight, slightly extending beyond middle of the wing; 

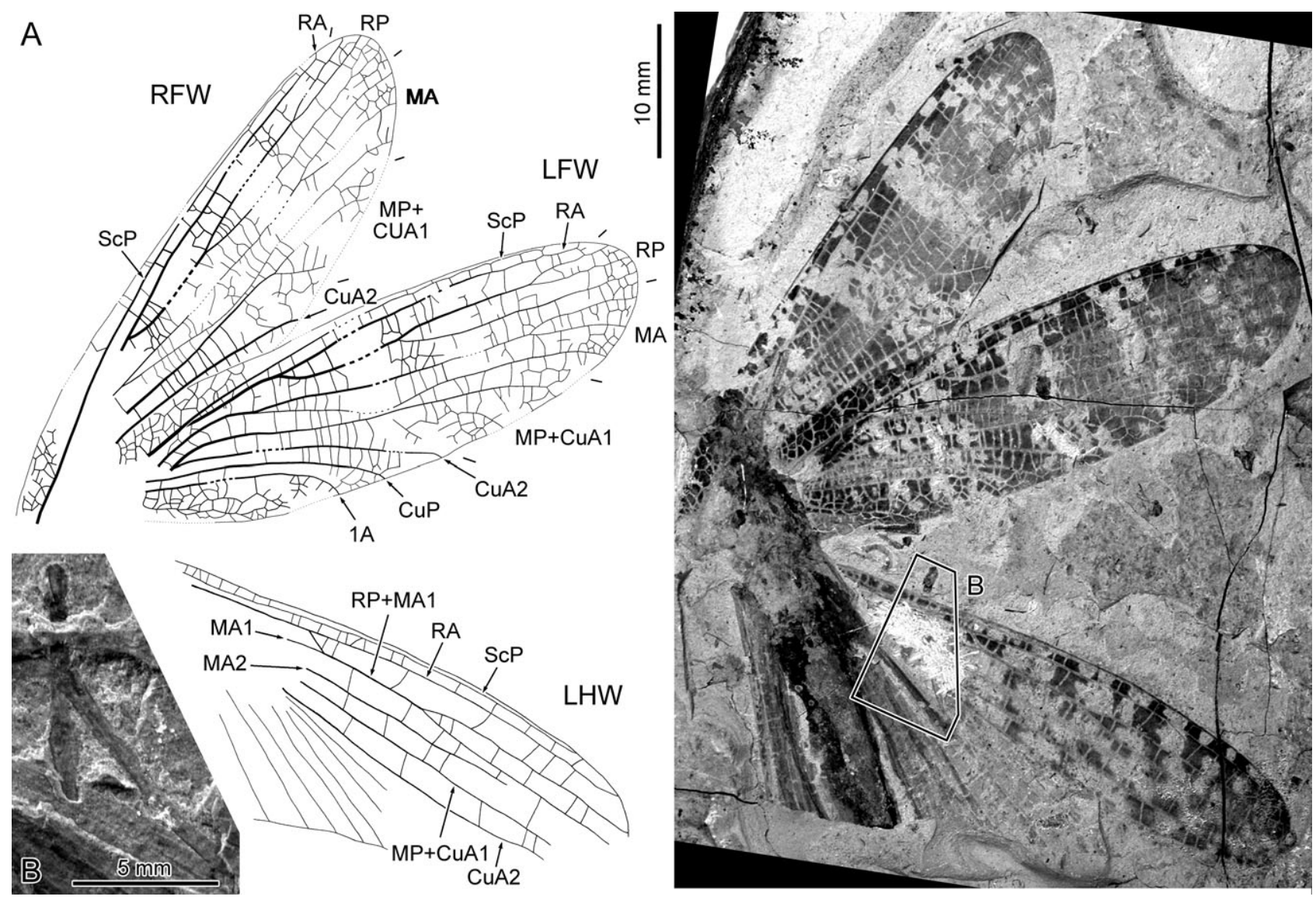

Fig. 1. Adjacivena rasnitsyni gen. n., sp. n., holotype, specimen CNU-PHA-NN2009001 (presumably $\uparrow)$. A - habitus, drawing and photograph (positive imprint, dry, reversed); B - photograph of right leg (as located on A but on the negative imprint).

CuP simple, slightly curved, ending nearly $2 / 5$ along the wing; 1A straight basally, bent posteriorly near wing margin; cross-veins numerous, forming reticulations along posterior wing margin and in broad areas; dark coloration, particularly basally and along the anterior wing margin, with pale spots forming 4 transverse pale stripes (apical one less clear), and also irregularly distributed along anterior wing margin. Left hind wings: only left hind wing with observable details; preserved length $39.0 \mathrm{~mm}$; area between anterior wing margin and ScP long and narrow; ScP nearly reaches the wing apex; RA simple, straight and parallel to ScP; RP fused with MA1; free RP $2.0 \mathrm{~mm}$ long, RP + MA1 $8.5 \mathrm{~mm}$ long; MA2 simple, vanishing distally (reaching MA?); MP + CuA1 and $\mathrm{CuA} 2$ simple and straight; 7 anal veins preserved, base of vannus not preserved; remigium with dark coloration, particularly apically and along the anterior margin, with pale spots often located within cells. Legs slender, moderately long, not armed and with a cover of fine setae.

Specimen CNU-PHA-NN2009003 (paratype; Fig. 2): moderately well-preserved specimen, complete right forewing, left forewing and left hind wing remains overlapping, left forewing and left hind wing hardly interpretable, incomplete and faint femora and tibiae of a pair of right legs, and moderately well-preserved end of the abdomen, positive imprint. Right forewing: preserved length about $38.2 \mathrm{~mm}$, width about $9.6 \mathrm{~mm}$; area between anterior wing margin and $\mathrm{ScP}$ wide proximally, tapers gradually towards wing apex; in proximal part, only a few reticulated cross-veins visible; ScP hidden under $\mathrm{R}$ basally, long and concave, reaching anterior wing margin close to wing apex; RP branched $25.1 \mathrm{~mm}$ distal to its origin; anterior branch of RP forked, posterior branch simple; MA forks basal to the origin of RP; MA2 weak and concave, approaches middle of MP + CuA1 but never joins it; MP + CuA1 with two branches; $\mathrm{CuA} 2$ simple, slightly curved. Left forewing: RP with 3 branches; MA1 forked distally (resulting branches indicated as * on Fig. 2). Left hind wing: R slightly curved, strong; RP fused with MA1; free RP (before fusion with MA1) about 1.7 mm long, RP + MA1 $12.4 \mathrm{~mm}$ long, RP and MA1 diverging distally. Abdomen: only terminal segments visible; genitalia (in dorsal view; Fig. 2B) composed of a pair of elongated valves (presumably gonapophysis 8) with left gonobasis visible, forming an ovipositor; occurrence of an operculum, partly hidden by visible valves (located above it), broader than valves at its base, extending distally to apices of valves, with distal portion broken off; cerci and gonapophysis 9 not visible/ preserved/present.

Specimen CNU-PHA-NN2009002 (Fig. 3): body length (excluding antennae) about $66 \mathrm{~mm}$; head and most of thorax obscured; abdomen long and slender, indistinct; femur and tibia of a right leg partly visible; terminalia including genital structures. Forewings: $41.8 \mathrm{~mm} /$ about $36 \mathrm{~mm}$ long (left / right forewings); area between anterior 
A

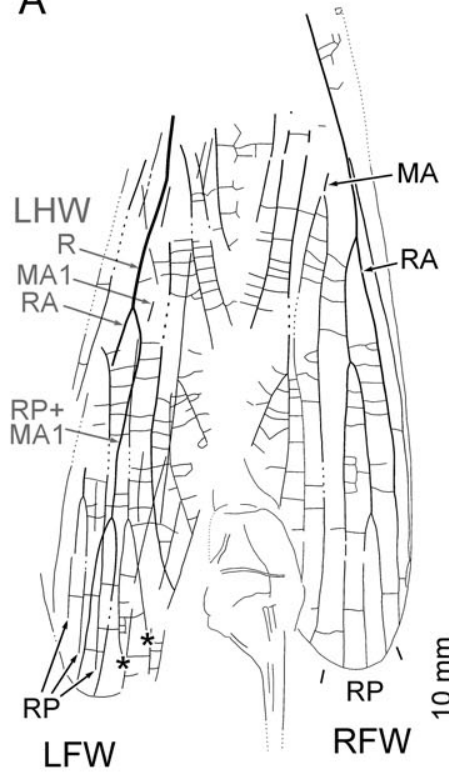

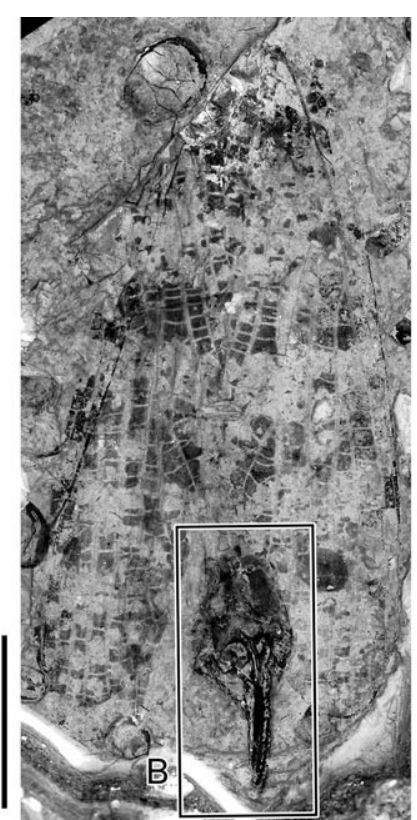

B

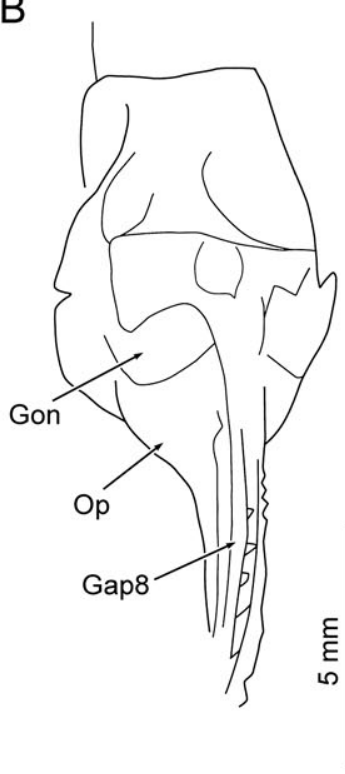

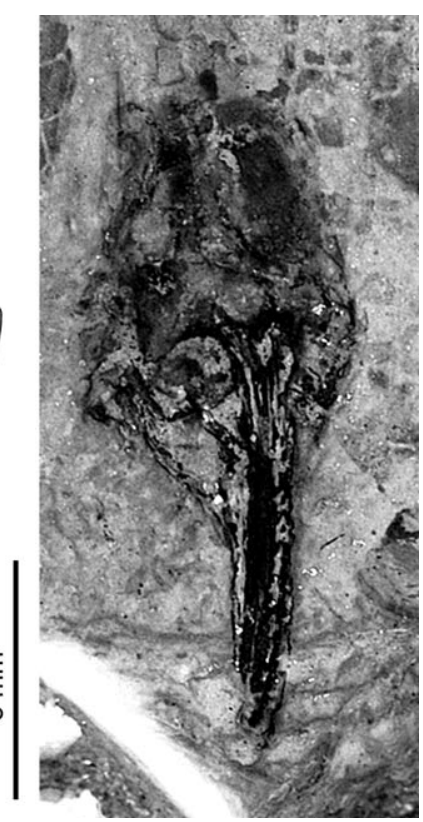

Fig. 2. Adjacivena rasnitsyni gen. n., sp. n., paratype, specimen CNU-PHA-NN2009003 ( $\%)$. A - habitus, drawing (* indicate branches of MA1 in left forewing) and photograph (positive imprint, under ethanol); B - genital structures, drawing and photograph (positive imprint, under ethanol; as located on A).

wing margin and ScP proximally wide, and tapers gradually; cross-veins poorly preserved in this area; R covering $\mathrm{ScP}$ at wing base; RA simple, slightly bent posteriorly opposite the origin of RP; RP branched $28.7 \mathrm{~mm} / 16.6$ $\mathrm{mm}$ distal to its origin; in left forewing, RP with 4 branches, first anterior branch reaching RA sub-apically; MA forked basal to the origin of RP; branches of MA simple; posterior branch of MA weak, concave, and approximating $\mathrm{MP}+\mathrm{CuA} 1$ opposite the first fork of RP; $\mathrm{MP}+\mathrm{CuA} 1$ forked distal to wing mid-length; $\mathrm{CuA} 2$ and $\mathrm{CuP}$ straight basally and curved posteriorly close to posterior margin; $\mathrm{CuP}$ weak, concave, distinct from the claval fold (* on Fig. 3) distally; area between 1A and posterior margin with irregular, reticulated cross-veins, and weak $1 \mathrm{~A}$ veinlets; slightly infuscate, with pale areas between $\mathrm{MP}+\mathrm{CuA} 1$ and $\mathrm{CuA} 2$, along the posterior branch of MA, and along $\mathrm{CuP}$, with narrow, irregular, oblique, pale stripes in distal $2 / 3$ of wing, and with irregularly scattered, small, pale spots; veins pale. Hind wings: preserved length $40.5 \mathrm{~mm}$ (left hind wing), estimated length about $49 \mathrm{~mm}$ (right hind wing); area between anterior wing margin and $\mathrm{ScP}$ narrow, distal part not preserved; RP diverging from $\mathrm{R} 18.6 \mathrm{~mm}$ distal to wing base; RP short (1.0 mm) before it fuses with MA1; RP + MA1 $7.1 \mathrm{~mm}$ long; MA1 (diverging from RP + MA1) 3.4 $\mathrm{mm}$ long before it fuses with MA2; MA1 + MA2 $2.9 \mathrm{~mm}$ long; $\mathrm{MP}+\mathrm{CuA} 1$ strong and convex, simple; $\mathrm{CuA} 2$ concave, simple; vannus with several anal veins, simple and straight, partly overlapping (indicating the occurrence of intercalary folds); cross-veins rarely reticulated in medial part of wing; very faint dark coloration, discernible in distal and posterior parts of wing, tending to form narrow transverse stripes apically. Abdomen: margins indistinct, dark alimentary canal well traceable. Terminalia (dorsal view) forming a prominent, broad structure; distinguish- able structures composed of two, ovoid, symmetrical structures (1 on Fig. 3B), of seemingly paired elements partly hidden by more dorsal parts (2), of a presumed cercus, unsegmented in the preserved part, and of a long and narrow element covered with 5 rows of thorns ( 3 on Fig. 3B; rows indicated by arrows on Fig. 3C).

Type material. Holotype specimen CNU-PHA-NN2009001, composed of positive and negative imprints (referred to as $\mathrm{P}$, and $\mathrm{C}$, respectively), presumably a female (see below); paratype specimen CNU-PHA-NN2009003 composed of a positive imprint, interpreted as a female.

Etymology. The species name is in honor of Prof. Alexandr Rasnitsyn (Paleontological Institute, Russian Academy of Sciences, Moscow).

Additional material. Specimen CNU-PHA-NN2009002, composed of positive and negative imprints (referred to as $\mathrm{P}$, and $\mathrm{C}$, respectively), interpreted as a male.

Type locality. Daohugou Village, Jiulongshan Formation, Ningcheng County, Inner Mongolia, China

Type strata. Bathonian - Callovian boundary, Middle Jurassic.

Discussion. The specimen CNU-PHA-NN2009003 (Fig. 2) differs from the holotype of Adjacivena rasnitsyni gen. n., sp. n. (Fig. 1) mainly in having a simple MA1 in the right forewing. However, MA1 in the left forewing is forked, suggesting that this trait is variable in this species.

The specimen CNU-PHA-NN2009002 (Fig. 3) is interpreted as male. Although structures observed in the terminalia are difficult to interpret, the long and narrow element indicated as " 3 " in Fig. 3B and reproduced in Fig. $3 \mathrm{C}$ is provided with thorns arranged in 5 oblique rows. This thorn pad recalls that occurring on extensions of the $10^{\text {th }}$ tergum in many male stick-insects (Bradler, 2009). The differences in the extended elements in extant forms, which are used to hold female genital during copu- 

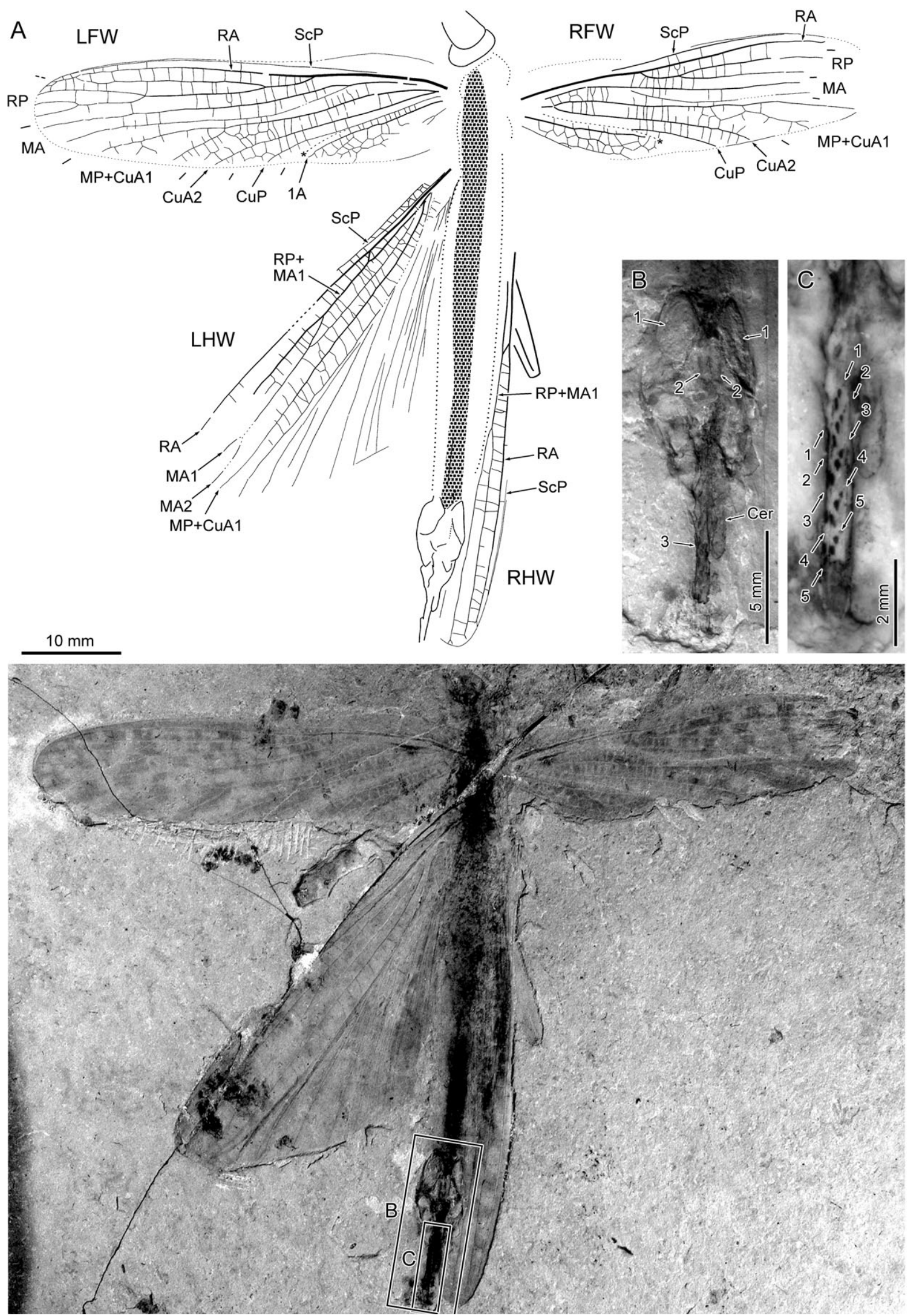

Fig. 3. Adjacivena rasnitsyni gen. n., sp. n., specimen CNU-PHA-NN2009002 (presumablyô). A - habitus, drawing (* indicate claval folds) and photograph (positive imprint, dry); B - genital structures, photograph (positive imprint, dry; as located on A); C detail of genital structures, photograph (positive imprint, under ethanol; "3" on B, and as located on A; arrows and numbers indicate rows of thorns). 

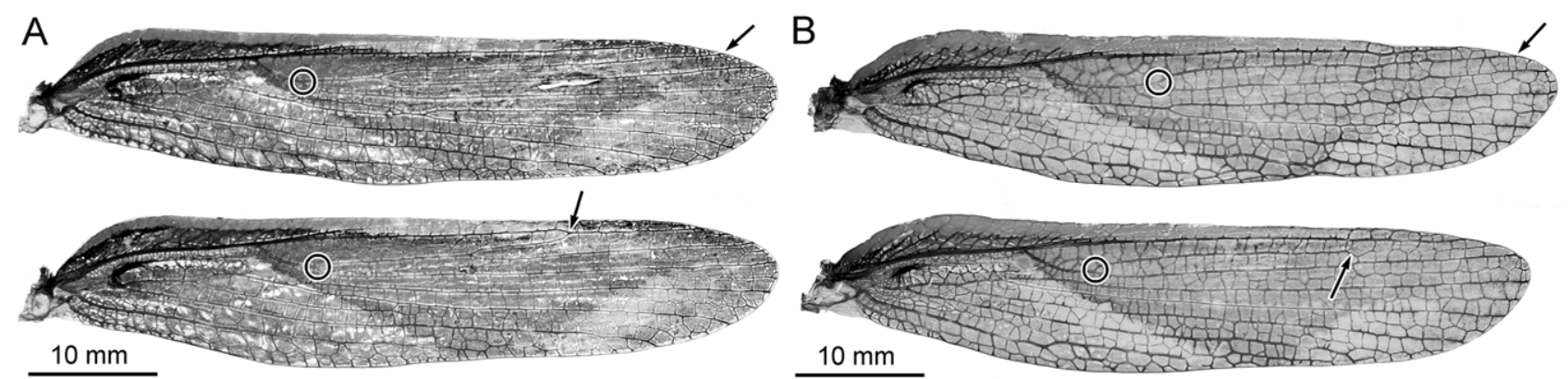

Fig. 4. Heteropteryx dilatata (Parkinson, 1798), photographs of forewings ( $₫$ ) (wings viewed using transmitted light; arrows indicate endings of the most anterior branches of RP; circles indicate the first forks of RP). A - specimen IWC OB 199, right and left forewings, dorsal and ventral view, respectively; B - specimen IWC OB 198 right and left forewings, dorsal and ventral view, respectively.

lation (sometimes in conjunction with other elements), and the fact that various "holding" structures such as the vomer have undergone homoplasic evolution (Bradler, 2009), suggest that it is reasonable to assume (1) an homology with the extensions of the $10^{\text {th }}$ tergum in stickinsects (regardless of their shape) because of the presence of a thorn pad, but that (2) the homology of the shape (viz. narrow and elongate) of the $10^{\text {th }}$ tergum extensions with that in some extant stick-insects (Bradler, 2009: Fig. $29)$ is dubious. This interpretation implies that specimen CNU-PHA-NN2009002 is a male stick-insect.

This specimen differs from the other specimens described herein as follows: (1) anterior branch of RP reaching RA, (2) location of the first fork of RP closer to the origin of RP, (3) absence of distinct pale stripes on forewings, and (4) in having a slender silhouette. Regarding (1), our observations on the venation of the forewing of $H$. dilatata indicate that such variation occurs at an intraindividual level in this related species (Fig. 4). The same applies to (2) (Fig. 4B). Provided that (a) sexual dimorphism is common, and sometimes very pronounced, in all extant stick-insects (Beier, 1968; Brock \& Hasenpusch, 2009; Key, 1991; among others), that (b) based on genitalia we interpret the specimen CNU-PHA-NN2009003 as a female and (c) the specimen CNU-PHA-NN2009002 as a male, then it is not unlikely that the specimen CNUPHA-NN2009002 is a male of the same species as the specimen CNU-PHA-NN2009003, and that the difference in forewing coloration (3) is a result of a sexual dimorphism in this species. In addition the specimen is more slender than others (4), a trait common in male stickinsects. Therefore we propose to avoid the erection of a possibly dubious species (for the specimen CNU-PHANN2009002) and provisionally assign it to Adjacivena rasnitsyni gen. n., sp. n. We assume that the holotype CNU-PHA-2009001 (Fig. 1) is a female, as its wing coloration is similar to that of specimen CNU-PHA-2009003. The discovery of a female specimen more closely similar to the specimen CNU-PHANN2009002, and/or of a male more closely similar to the specimen CNU-PHA-NN2009003, would invalidate our provisional hypothesis.

Forewings of the specimen CNU-PHA-NN2009002 strongly differ in size (Fig. 3). This difference is not unusual (see Fig. 4B) and might be explained by a developmental "glitch" and/or as the effect of a parasite.

Little is known about Adjacivenia reticulata (Kuzmina, 1985) comb. n. (Kuzmina, 1985: Fig. 1d \& P1. V, Fig. 7). However, the pattern of coloration on the forewing strongly differs from that of specimens assigned to Adjacivena gen. n., sp. n.

\section{DISCUSSION}

Although interpretation of the genital structures is difficult because compression has resulted in the superimposition of various elements, the orientation of the specimen and the uneven plane of splitting through the corresponding structures of the material we describe indicate that in the females of Adjacivena rasnitsyni gen. n., sp. n. the ovipositor is concealed by an operculum, and in the males there is an extension on the $10^{\text {th }}$ tergum with a thorn pad. These structures are diagnostic of stick-insects. If this interpretation is correct, this material supports the view that the Susumanioidea are genuine stem-Phasmatodea (Gorochov, 2000).

Another interesting aspect of the material described herein regards intra-specific variability in wing venation. This aspect has received little consideration, with deleterious consequences for the taxonomy of Palaeozoic and Mesozoic fossil insects (Béthoux, 2009). The use of material of recent species to delimit the fossil ones more accurately is rare (Béthoux et al., 2010; Schneider, 1977) despite its broad potential (Béthoux, 2008). In our case a selected sample of individuals of a single fossil species demonstrated that differences that could have been perceived as a species-relevant were most likely not.

Because of their completeness, the fossil specimens described herein allow further investigation of the variability of characters that are absent in recent related taxa. In the specimen CNU-PHA-NN2009001 (Fig. 1) RP has a total of 4 and 3 distal branches, in the right and left forewings, respectively. The location of the fork of MA1 also varies. In the specimen CNU-PHA-NN2009003 (Fig. 2), MA1 is simple in the right and distally forked in the left forewing. This material and additional data on recent material might prompt a species level revision of the Susumaniidae. 
The new material is particularly helpful in resolving the primary homology of the hind wings of Susumaniidae. Based on three exceptionally well-preserved fossil specimens, Ren (1997) suggests that the forked "RP-lookinglike" vein is actually a composite stem, composed of a simple RP and a simple MA1 ("MA" using Ren's interpretation). This assumption is supported by the occurrence of a fusion of a "median" element with RP near the origin of the latter (Ren, 1997: Figs 2, 3). Despite this evidence, Gorochov (2000) interpreted the corresponding vein as a forked RP. The newly described material confirms that in Susumaniidae a part of the median vein fuses with RP over some distance. The comparatively short distance over which RP and MA1 are fused in Adjacivena rasnitsyni gen. n., sp. n. could be a plesiomorphic state and the greater distance over which they are fused in other Susumaniidae, a more advanced state. If the Susumaniidae are stem-stick-insects, the possibility that "RP" is actually composed of RP and "median" element(s) will have to be taken into consideration in future comparative analyses of the hind wing venation of stick-insect (O.B., in prep.).

\section{CONCLUSION}

The new specimens confirm the interpretation that, in fossil putative stem-Phasmatodea, a composite stem involving RP and a part of the median system occurs in hind wings (Ren, 1997). The review of the data in the literature undertaken for the systematic treatment revealed that the current framework is unsatisfactory. A number of species have been erected based on very fragmentary remains and might better be considered as dubious. In addition several genera have been erected based only on forewings and others only on hind wings. The material described by Ren (1997) and herein indicate that such "groupings" might be taxonomically invalid because these distinct organs could be present in the same taxon. Should a systematic revision be undertaken, fossil specimens with both fore- and hind wings, such as those described herein, will be very useful.

ACKNOWLEDGEMENTS. Authors are grateful to three anonymous reviewers for their constructive comments. The first author is deeply indebted to A. Rasnitsyn (Paleontological Institute, Russian Academy of Sciences, Moscow) for his kind assistance with drawings, his improvement of an earlier version of the manuscript. A. Rasnitsyn and A. Nel (MNHN, Paris) facilitated access to data in the literature. Authors are grateful to C.-K. Shih (College of Life Science, Capital Normal University, Beijing) for revision of the manuscript and to S. Bradler (Göttingen University, Göttingen) and P. Brock for their help with the interpretation the genital organs. This research was supported by the National Natural Science Foundation of China (No. 40872022, 31071964), Nature Science Foundation of Beijing (No. 5082002), the Scientific Research Key Program (KZ200910028005) and PHR Project of Beijing Municipal Commission of Education.

\section{REFERENCES}

BeIER M. 1968: Phasmida (Fangheuschrecken). In Helmcke J.G., Starck D. \& Wermuth H. (eds): Handbuch der Zoologie. Walter de Gruyter, Berlin, pp. 1-56.

BÉTHOux O. 2008: The insect wing collection project 4. Bonner Paläoentomologen-Treffen, Bonn. Dt. Ges. Allg. Angew. Entomol. Nachr. 24: 24-25.

BÉтHоux O. 2009: Gaps and nodes between fossil and extant insects. Syst. Entomol. 34: 599-609.

Béthoux O., Beckemeyer R.J., Engel M.S. \& Hall J.D. 2010: New data on Homocladus grandis, a Permian stem-mantodean (Polyneoptera: Dictyoptera). J. Paleontol. 84: 746-753.

Birket-Smith S.J.R. 1981: A wing of Phasmida from the Cretaceous period (Insecta). Entomol. Scand. 12: 245-249.

Bolton H. 1925: Insects from the Coal Measures of Commentry. BMNH, London, $56 \mathrm{pp}$.

Bradler S. 2009: Phylogeny of the stick and leaf insects (Insecta: Phasmatodea). Species, Phylogeny Evol. 2: 3-139 [in German with English abstr.].

Bradler S. \& Buckley T.R. 2011: Stick insect on unsafe ground: does a fossil from the early Eocene of France really link Mesozoic taxa with the extant crown group of Phasmatodea. Syst. Entomol. 36: 218-222.

Bragg P.E. 2001: Phasmids of Borneo. Natural History Publications (Borneo), Kota Kinabalu, 772 pp.

Brock P.D. \& Hasenpusch J. 2009: The Complete Field Guide to Stick and Leaf Insects of Australia. CSIRO Publishing, Australia, 204 pp.

BRUNNER vON WATtenwyl C. 1893: Révision du système des orthoptères et description des espèces rapportées par $\mathrm{M}$. Leonardo Fea de Birmanie. Ann. Mus. Civ. Stor. Nat. Genova G. Doria 33: 1-230.

CARPENTER F.M. 1992: Superclass Hexapoda. In Kaesler R.L. (ed.): Treatise on Invertebrate Paleontology. The Geological Society of America and the University of Kansas, Boulder, $\mathrm{xxii}+655 \mathrm{pp}$.

Cui Y.Y., Béthoux O., Shin C.K. \& Ren D. 2010: A new species of the family Juraperlidae (Insecta: Grylloblattida) from the Middle Jurassic of China. Acta Geol. Sin. 84: 710-713.

Delclòs X., Nel A., Azar D., Bechly G., Dunlop J.A., Engel M.S. \& Heads S.W. 2008: The enigmatic Mesozoic insect taxon Chresmodidae (Polyneoptera): New palaeobiological and phylogenetic data, with the description of a new species from the Lower Cretaceous of Brazil. N. Jb. Geol. Paläontol. Abh. 247: 353-381.

Gorochov A.V. 1988: On the classification of orthopteran insects of the subfamily Phasmomimoidea (Orthoptera) with descriptions of new taxa. Trudy Zool. Inst. Akad. Nauk SSSR 178: $32-44$ [in Russian].

Gorochov A.V. 1992: New fossil orthopterans (Orthoptera) and a stick-insect (Phasmoptera) from Mesozoic and Paleozoic of Mongolia. Tr. Sovm. Rus.-Mongol. Paleontol. Exp. 41: 117-121 [in Russian].

Gorochov A.V. 1993: Fossil stick-insects (Phasmoptera) from Jurassic and Cretaceous. Trudy Paleontol. Inst. Akad. Nauk SSSR 252: 112-116 [in Russian].

Gorochov A.V. 1994: Permian and Triassic walking sticks (Phasmoptera) from Eurasia. Paleontol. J. 28(4): 83-98.

Gorochov A.V. 2000: Phasmomimidae: are they Orthoptera or Phasmatoptera? Paleontol. J. 34: 295-300.

Gorochov A.V. \& Rasnitsyn A.P. 2002: Superorder Gryllidea Laicharting, 1781 (= Orthopteroidea Handlirsch, 1903). In Rasnitsyn A.P. \& Quicke D.L.J. (eds): History of Insects. Kluwer Academic Publishers, Dordrecht, pp. 293-303. 
Grimaldi D. \& Engel M.S. 2005: Evolution of the Insects. Cambridge University Press, Cambridge, $x v+755$ pp.

Kevan D.K.M. \& Wighton D.C. 1981: Paleocene orthopteroids from south-central Alberta, Canada. Can. J. Earth Sci. 18: $1824-1837$.

Key K.H.L. 1991: Stick-insects. In Naumann I.D., Crane P.B., Lawrence J.F., Nielsen E.S., Spradbery J.P., Taylor R.W., Whitten M.J. \& Littlejohn M.J. (eds): The Insects of Australia, a Textbook for Students and Researchers. Melbourne University Press, Melbourne, pp. 394-404.

Kuzmina S.A. 1985: New orthopterans of the family Phasmomimidae from the Lower Cretaceous of Transbaikalia. Paleontol. J. 19(3): 56-63.

Martynov A.V. 1928: A new fossil form of Phasmatodea from Galkino (Turkestan), and on Mesozoic Phasmids in general. Ann. Mag. Nat. Hist. 1: 319-328.

Nel A., Marchal-Papier F., Béthoux O. \& Gall J.-C. 2004: A "stick insect-like" from the Triassic of The Vosges (France) (Insecta: "Phasmatodea"). Ann. Soc. Entomol. Fr. 40: 31-36.

Nel A., Delfosse E., Robillard T. \& Petrulevičius J.F. 2010: An early winged crown group stick insect from the Early Eocene amber of France (Insecta, Phasmatodea). Syst. Entomol. 40: 31-36.

Parkinson J. 1798: Description of the Phasma dilatatum. Trans. Linn. Soc. Lond. 4: 190-192.

RAGGe D.R. 1955: The wing-venation of the order Phasmida. Trans. R. Entomol. Soc. Lond. 106: 375-392.

REN D. 1997: First record of fossil stick-insects from China with analyses of some palaeobiological features (Phasmatodea: Hagiphasmatidae fam. nov.). Acta Zootax. Sin. 22: 268-282.

Ren D., Lu L.W., Guo Y.G. \& Ji S.A. 1995: Faunae and stratigraphy of Jurassic-Cretaceous in Beijing and the adjacent areas. Seismic Publishing House, Beijing, 222 pp.
Ren D., Gao K.Q., Guo Y.G., Ji S.A., Tan J.J. \& Song Z. 2002: Stratigraphic division of the Jurassic in the Daohugou area, Ningcheng, Inner Mongolia. Geol. Bull. China 21: 584-591.

Ren D., Labandeira C.C. \& Shih C.K. 2010: New Mesopsychidae (Mecoptera) from Northeastern China. Acta Geol. Sin. 84: 720-731.

Rice H.M.A. 1969: An antlion (Neuroptera) and a stonefly (Plecoptera) of Cretaceous age from Labrador, Newfoundland. Geol. Surv. Can. 68: 1-12.

SCHNEIDER J.W. 1977: Zur Variabilität der Flügel paläozoischer Blattodea (Insecta), Teil I. Freiberg. Forschungsh. (C) 326: 87-105.

Sharov A.G. 1968: Phylogeny of the orthopteroid insects. Trudy Paleontol. Inst. Akad. Nauk SSSR 118: 1-216 [in Russian].

Sharov A.G. 1971: Phylogeny of the Orthopteroidea. B.B. Rodendorf, Jerusalem, Israel Program for Scientific Translations, vi $+251 \mathrm{pp}$.

TAN J. \& Ren D. 2002: Palaeoecology of insect community from Middle Jurassic Jiulongshan Formation in Ningcheng County, Inner Mongolia, China. Acta Zootax. Sin. 27: 428-434.

Tilgner E. 2000: The fossil record of Phasmida (Insecta: Neoptera). Insect Syst. Evol. 31: 473-480.

Tillyard R.J. 1918: Mesozoic insects of Queensland. 3. Odonata and Protodonata. Proc. Linn. Soc. N.S.W. 43: 417-435.

Wedmann S., Bradler S. \& Rust J. 2007: The first fossil leaf insect: 47 million years of specialized cryptic morphology and behavior. Proc. Natl. Acad. Sci. USA 104: 565-569.

WillmanN R. 2003: Die phylogenetischen Beziehungen der Insecta: Offene Fragen und Probleme. Ver. Westd. Entomol. Tag 2001: 1-64.

Zhao J.X., Ren D. \& Shiн C.K. 2010: Enigmatic earwig-like fossils from Inner Mongolia, China. Insect Sci. 17: 459-464.

Received January 17, 2011; revised and accepted June 20, 2011 